\title{
Application of X-ray microtomography to the microstructural characterization of Al-based functionally graded materials
}

\author{
A. Velhinho1, a, F. M. Braz Fernandes ${ }^{1, b}$, S.C. Ferreira ${ }^{1, c}$, L.A. Rocha ${ }^{2, d}$, \\ G. Vignoles ${ }^{3, e}$, P. Cloetens ${ }^{4, f}$ \\ ${ }^{1}$ CENIMAT - Centro de Investigação em Materiais, Faculdade de Ciências e Tecnologia, \\ Universidade Nova de Lisboa, Quinta da Torre, Caparica 2829-516, PORTUGAL
}

${ }^{2}$ CIICS - Centro de Investigação em Interfaces e Comportamento de Superfícies, Universidade do Minho, Campus de Azurém, Guimarães 4800-058, PORTUGAL

${ }^{3}$ Laboratoire des Composites Thermostructuraux, Université de Bordeaux 1, Domaine Universitaire 3, Allée la Boétie, F 33600 Pessac, FRANCE

${ }^{4}$ ESRF - European Synchrotron Radiation Facility, Polygone Scientifique Louis Néel - 6, rue Jules Horowitz, 38000 Grenoble, FRANCE

aajv@fct.unl.pt, ${ }^{b}$ fbf@fct.unl.pt, ${ }^{c}$ sccf@fct.unl.pt, ${ }^{d}$ Irocha@dem.uminho.pt, evinhola@lcts.u-bordeaux1.fr, ${ }^{\mathrm{f}}$ cloetens@esrf.fr

Keywords: Computed tomography, Microtomography, Image analysis, Data processing, Metal matrix composites, Functionally graded materials, Microstructure, Interface, Damage.

\begin{abstract}
This paper provides a brief overview of the possibilities offered by X-ray computed microtomography, and particularly synchrotron radiation X-ray microtomography, regarding metal matrix composite characterization, emphasis being placed in the case of Al-based functionally graded materials. Examples are provided concerning the characterization of the reinforcement population, interfacial properties, in-situ transformation and damage evolution. The specific needs of the technique and limitations to its widespread use are mentioned.
\end{abstract}

\section{Introduction}

Al-matrix composites reinforced with $\mathrm{SiC}$ particles have attracted a growing interest from the automotive, aeronautical and aerospace industries, due to their advantageous toughness-to-weight ratios, combined with the possibility of employing conventional casting technologies. Furthermore, through an adequate control of the ceramic particles distribution from the part surface down to its core, the conventional metal-matrix composite (MMC) may become a functionally graded metal matrix composite (FGMMC) in which the wear resistance is expected to be improved at the surface whilst a high global toughness is preserved throughout the bulk of the component. In consequence, previous and ongoing research has been concerned with processing and characterization of SiC particle-reinforced functionally graded aluminium-matrix composites: studies concerning identification of key processing parameters and resulting reinforcement profiles [1-4], wear [5] and tribocorrosion [6] behaviour have been published.

Researchers investigating Al-based functionally graded materials (FGM), be it in the form of coatings or bulk FGMMCs, are usually concerned with a wide range of characterization problems.

3D geometrical characterization, if correctly addressed, may reveal itself as a profitable tool, guiding the researcher towards the elucidation of several material issues. These may deal primarily with the reinforcing constituent - determination of morphology and other surface characteristics, nature of the constituent, spatial distribution (location-wise, as well as orientation-wise), volume fraction and assessment of interactions within elements of the reinforcement population - or be concerned with the characterization of the interfaces between dissimilar constituents within the FGM - pore space volume and distribution, topology of the metal/ceramic interface.

Furthermore, in-situ studies of the solid/liquid interactions are of undoubtful interest to the development and optimization of the processing techniques to be applied for FGM production, 
while in-situ characterization of internal damage holds a particular significance if knowledge is to be gained regarding material behaviour.

To answer many of the above questions, X-ray computed microtomography (CT) may provide interesting approaches. Indeed, CT has already been proven as a useful technique to study such questions, even if the practical applications did not always involve FGMs, but rather other types of materials, such as metal alloys, ceramics, metal- and polymer-foams, non-graded MMCs and fiberreinforced ceramic-matrix composites, biomaterials, etc [7].

Thus, for the purpose of the present work, different CT application examples will be presented, in order to illustrate the possibilities of the technique, as well as some of the most recent developments regarding the tomographic study of Al-based FGMMCs.

\section{Principle, variants and limitations}

The basic principle of CT is summarized by Salvo et al. [8]. A series of radiographic images taken from different angles of the sample are recorded and subsequently recombined (convoluted) in order to obtain a virtual reconstruction of its volume, giving access to interior features within the special resolution limits. These can be as low as c. $1 \mu \mathrm{m}$, provided a highly coherent X-ray beam with a small angular divergence, such as synchrotron radiation, is used, in which case the technique is called Synchrotron Radiation X-ray Microtomography (SXMT).

The normal CT mode of operation corresponds to absorption, where the contrast between the sample constituents is due to the intrinsic differences in linear attenuation coefficients (related to atomic number and density). With SXMT, due to the beam coherency, two other modes of operation become available [8]: phase contrast edge-detection, similar to attenuation CT, but corresponding to interference between differentially-retarded parts of the plane wave, which takes place at media interfaces; and holotomography, resulting from the combination of images of the sample recorded with varying sample-detector distances.

As shown for the case of $\mathrm{Al} / \mathrm{SiC}_{\mathrm{p}}$ FGMMCs [9], the holographic modification of the CT method allows the reconstruction of neatly contrasted images, as opposed to classical CT; this aspect is emphasised in Fig. 1.

There are, however, some practical difficulties regarding the use of the technique - synchrotron radiation source availability, specific sample requirements, volume of the resulting datasets and resulting computing power needs - which must be taken into account when planning any SXMT experiment, and which constitute the main deterrent from widespread use.

\section{Characterization of the reinforcement population}

Considering the general case of composites, a promising field of application for CT corresponds to the study of different aspects regarding the reinforcement phases, taking advantage of the possibility to produce 3-D maps of the material, discriminating between the constituents present. Although bench-type CT apparatus may be in some cases sufficient, SXMT, with its high resolution, offers a distinct advantage for this task.

Surface characteristics. Masad and co-workers [10], working with granular materials of geological origin, used CT-images, coupled with different computation methods, to describe several surface characteristics of the particles, such as their morphology, angularity and texture. This approach could be extended to the study of composite particles, where particle surface characteristics are relevant, e.g. to understand how the reinforcements are affected by processing conditions. 


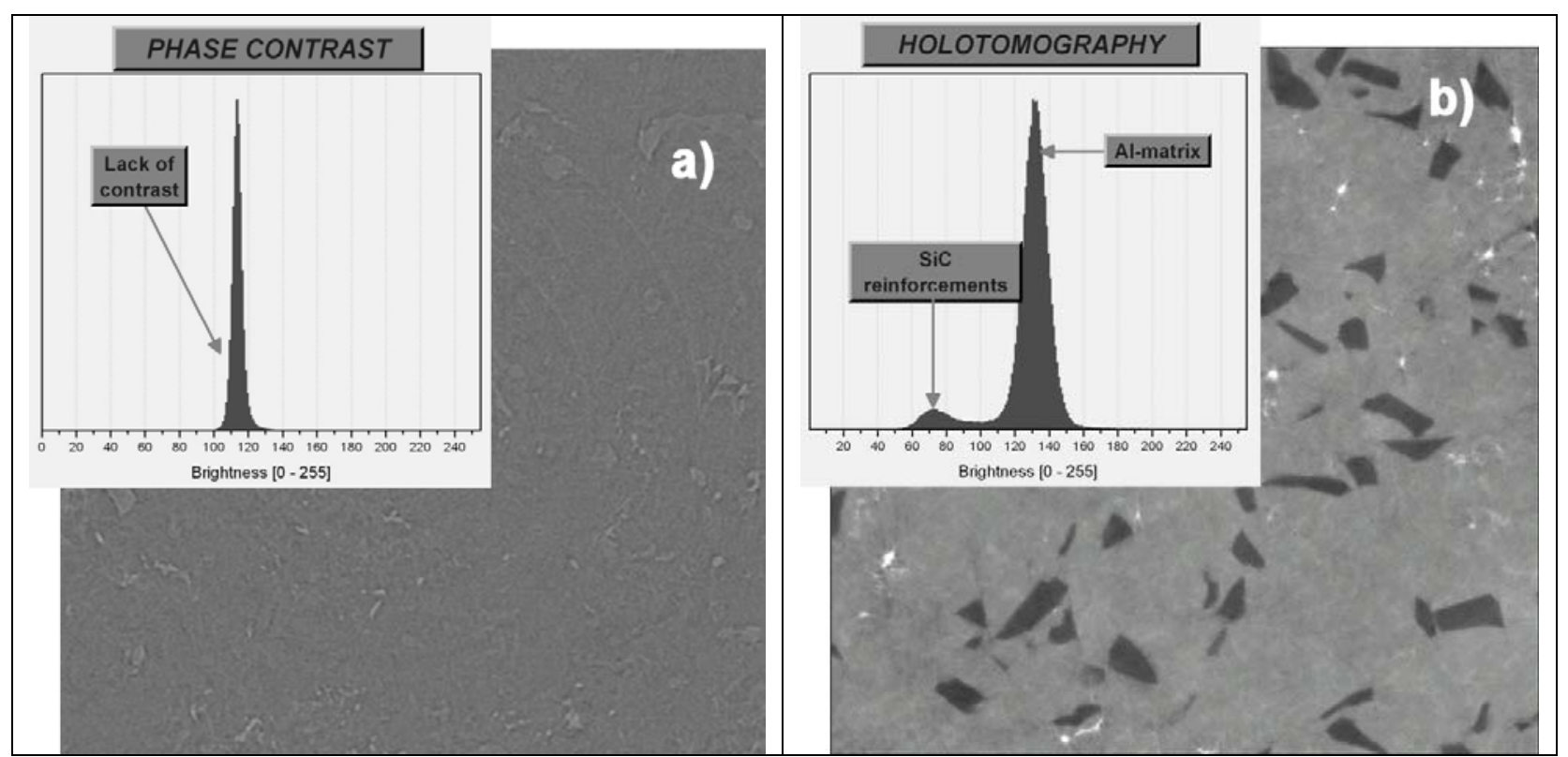

Figure 1 - a) Raw image obtained in the phase-contrast mode; the SiC particles are virtually undistinguishable. The weak $\mathrm{Al} / \mathrm{SiC}_{\mathrm{p}}$ contrast requires the use of a purposely developed segmentation technique, exploiting the interference fringes occurring near the matrix/reinforcement interfaces. b) Raw image obtained in the holotomographic mode, clearly showing the location of the SiC reinforcing particles. Given the strong matrix/reinforcement contrast, no special segmentation procedure is needed, allowing for a more accurate 3-D reconstruction of the particle morphology.

Fig. 2 illustrates a comparison between the effective morphology of SiC particle reinforcements, as revealed by SEM, and their rendering by SXMT, when operating in the phase-contrast mode, as described in detail in reference [11]. It is possible to see that the algorithm applied to overcome the weak contrast between the $\mathrm{SiC}$ reinforcements and the $\mathrm{Al}$ matrix, originally developed by Vignoles [12], results in some loss of spatial resolution, denoted by the round-edged reconstructed reinforcing particles, as seen in Fig. 2b). This problem, however, is solved through the use of the holotomographic mode.

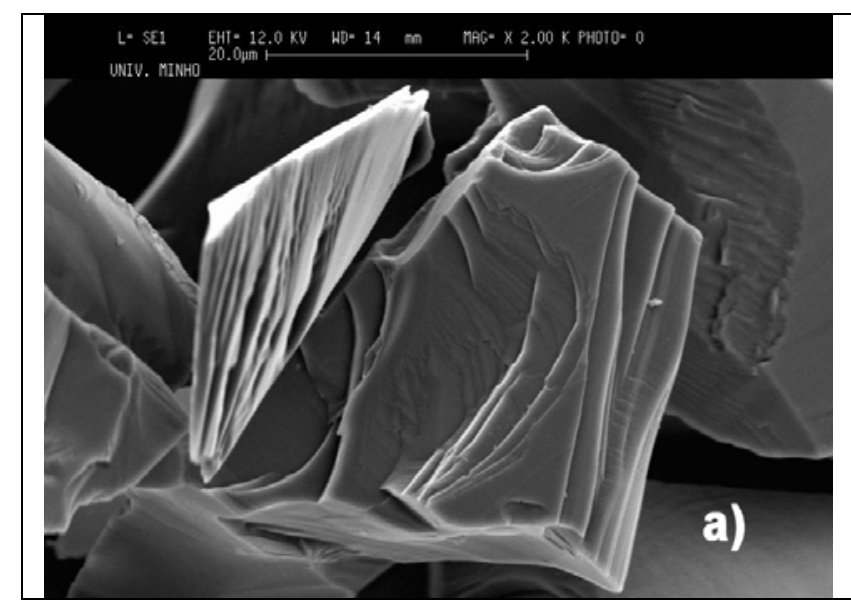

Figure 2 - Comparison between SiC particle morphology: a) as revealed by SEM; b) as reconstructed from phase-contrast mode SXMT.

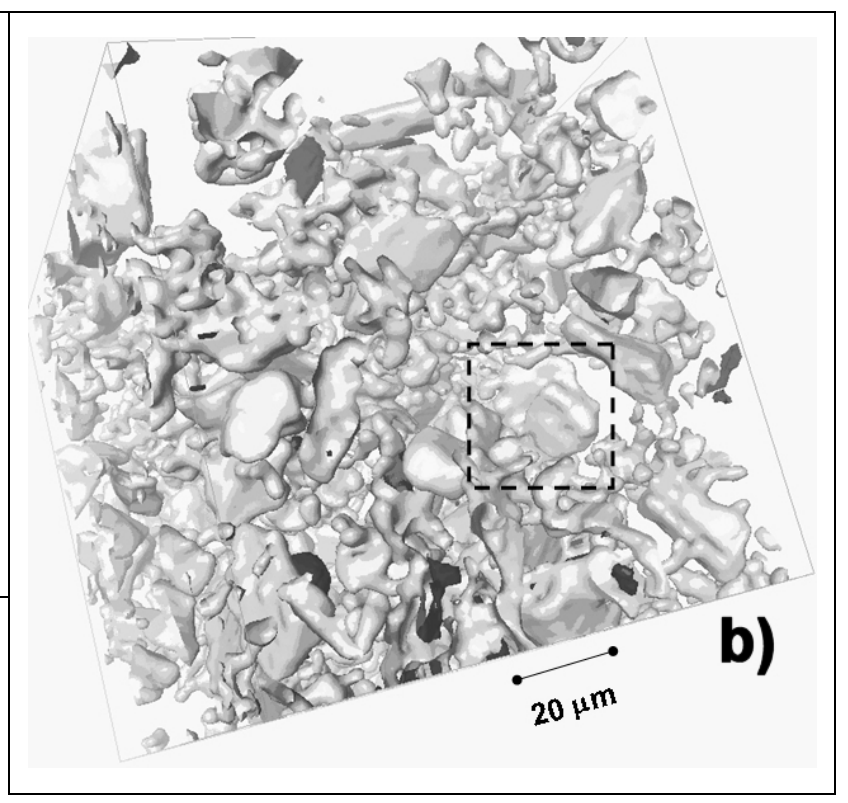

Chemical nature of constituents. On most situations, when contemplating CT techniques, researchers have already developed a sound knowledge about their samples chemistry and 
constituent identity. However, special situations may be conceived, e.g. when working with in-situ composites (where the reinforcing phases are only formed during cooling from the melt) [13], where the need may arise for phase identification. Such a task will not, by itself, justify the use of CT, but can nevertheless be performed alongside other types of characterization, provided the relevant phases present some morphological specificity or tend to occur at specific sites. This very principle was applied by De Vetter et al. [14] on a different context, in order to detect the presence of siloxanes/silanes mixtures in wood specimens. For this work, a scanning electron microscope, equipped with an energy dispersive X-ray spectrometer was used in order to obtain local tomographic reconstructions of the samples.

Spatial distribution. For any composite, the reinforcement distribution has a two-fold relevance. Firstly, the presence of reinforcing particles is directly implied on the local mechanical properties, with reflection on the overall properties of the composite. On the other hand, the presence of reinforcement clusters will bring a higher probability of crack nucleation, i.e. fatigue failure. Furthermore, in the case of FGMMCs, featuring engineered gradual transitions in reinforcement volume fraction and/or size, the existence of both reinforcement-rich and reinforcement-poor regions is inherent to the very nature of the material; in such a case, a smooth transition between those regions must be assured, while at the same time avoiding particle clustering or total depletion.

Although information about spatial distribution can be obtained by careful spatial correlation of 2D imaging [15, 16], the pertaining techniques are labour-intensive. Furthermore, there are stereological limits to the nature of the information thus gathered, since parameters regarding number of occurrences are out of reach of 2D-based analysis [17].

The application of phase-contrast SXMT to an $\mathrm{Al} / \mathrm{SiC}_{\mathrm{p}}$ FGMMC $[11,18]$ resulted in the curves shown in Fig. 3, where the longitudinal gradient for the ceramic particles (but also for pores) can be observed. The SiC-particle gradient thus found is in accordance with results from other techniques $[3,4]$.

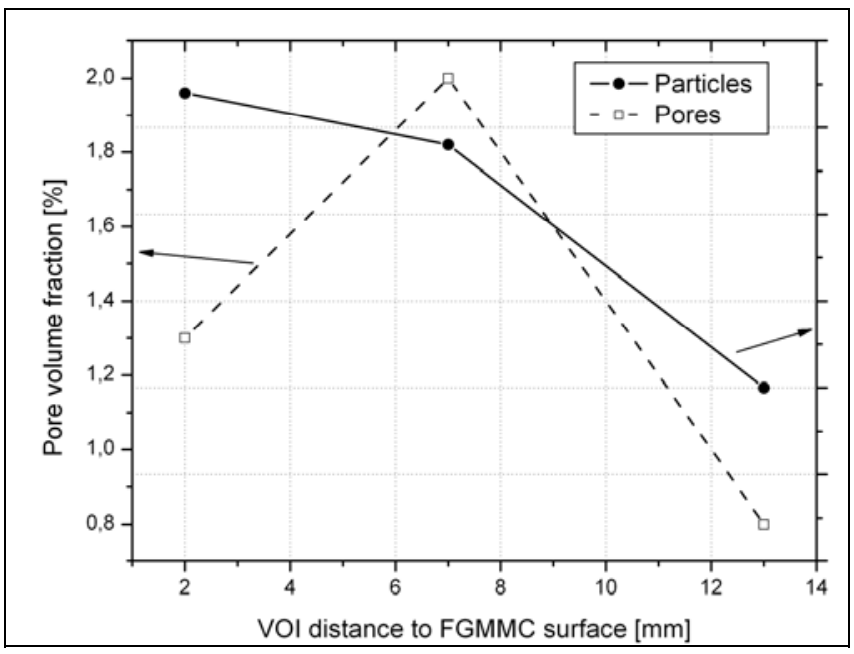

Figure 3 - Longitudinal profiles corresponding to the volume fractions of $\mathrm{SiC}$ particles and pores found in an Al-based FGMMC studied by SXMT.

A similar approach was used by Hamilton et al. in order to characterize the spatial distribution of $\mathrm{Al}^{-\mathrm{TiB}_{2}}$ MMCs [19], whereas the above reported use by De Vetter and co-workers of SEM/EXAFS-based local micro-CT on wood samples [14] resulted in the determination of the spatial determination of the impregnant substances.

When the reinforcement is non-equiaxed, it becomes essential to characterize its spatial distribution in terms not only of position, but also of orientation. SXMT has been used to perform this type of characterization on carbon-fibre reinforced carbon-matrix composites [12, 20], as well as on fibrous networks of low density wood-based boards [21]. Current work at Universidade Nova de Lisboa (UNL) aims at the development of a computing tool capable of determining the spatial 
orientation distribution of the reinforcements in an MMC tomographic sample, based on a 2D method described by Watanabe et al. [22].

Inter-particle interactions. The role of particle clustering on the fatigue behaviour of MMC/FGMMC materials was evoked previously. Again, this is a field were 2D methods have been proposed [23-25], but are bound by stereological constraints. SXMT in the holotomographic mode was successfully used to determine the magnitude of particle-particle contacts within a centrifugally-cast $\mathrm{Al} / \mathrm{SiC}_{\mathrm{p}}$ [26]: particle clustering was found to increase with a decreasing mean particle size, whereas this parameter increases as a function of the number of particles within a cluster.

\section{Interfacial characterization}

The matrix/reinforcement interface plays a decisive role in determining several properties and behaviours of MMCs. It is a region of varying chemical composition, which must insure the load transfer from the matrix to the reinforcements. Furthermore, its replacement by other types of interface (gas/ceramic, ceramic/ceramic) often denotes the occurrence of material defects, arising from processing problems and resulting in degraded properties. Thus, precise knowledge of the interfaces present in the material is paramount when studying MMCs and FGMMCs.

Through the application of SXMT to $\mathrm{Al} / \mathrm{SiC}_{\mathrm{p}}$ FGMMCs, Velhinho and co-workers $[11,18]$ studied the disruption caused in the formation of sound $\mathrm{Al} / \mathrm{SiC}$ interfaces by different types of porosities, characterized by differing shapes. Three sources of hindrance to metal/ceramic formation were identified: gas bubbles, either formed due to decreases in the solubility of the melt during solidification, or consisting of gases entrained by agitation of the slurry during processing; the presence of particle clusters, acting during solidification as barriers to the penetration of liquid aluminium; and solidification shrinkage, whose relevance to the disturbance of metal/ceramic interfaces was considered secondary, since it predominantly concerns the aluminium matrix.

\section{In-situ microtomography studies}

Apart from studies under static conditions, CT and SXMT have been used to visualise the evolution of different phenomena in real time, during so-called in-situ experiments.

Solidification and sintering. Extensive work has been performed in order to elucidate solidification phenomena with relevance to the resulting material microstructure. Columnar to equiaxed transition characteristics of Al-Cu [27] and Al-Ni [28] alloys are among the successful applications of SXMT to the in-situ study of solidification.

Similarly, Lame et al. [29] have applied the in-situ capability of SXMT to study the sintering process for $\mathrm{Cu}$ - and $\mathrm{Fe}$-based powders.

Plastic deformation and internal damage characterization. The deformation behaviour of metallic materials has been the object of SXMT in-situ studies, either in the case of aluminium [30] or Al-based syntactic MMCs [31]. Further attention has been devoted to the in-situ observation of cracks in Al and its alloys [8, 32-36], Al-based foams [8], conventional MMCs [37, 38] and syntactic foams [39]. Given the abundance and rate of new publications, this constitutes a very active and promising field.

\section{Further development and possibilities}

Data processing. As evidenced above, one of the major problems concerning the practical use of SXMT concerns the large size of the datasets obtained, requiring a powerful computing capability and often leading to long processing times. Parallel computing seems to be one of the ways to shorten these times. Based on the Vignoles algorithm [12], work at UNL has been developed in order to implement it on a multi-processor environment, some preliminary results being presented 
in Fig. 4. Hysteresis, the most time-consuming operation in the algorithm, performed in order to fully close each object, was chosen to demonstrate the gains obtained with parallel computing. These gains reach a factor of $\sim 9$ when processing a $100 \times 100 \times 100$ voxel dataset from an $\mathrm{Al} / \mathrm{SiC}_{\mathrm{p}}$ FGMMC tomograph (each voxel being a $0.95^{3} \mu \mathrm{m}^{3}$ cube), even if, as could be expected, a $64 \times$ increase in the volume of the dataset causes the processing time to increase by a factor of $\sim 73$.
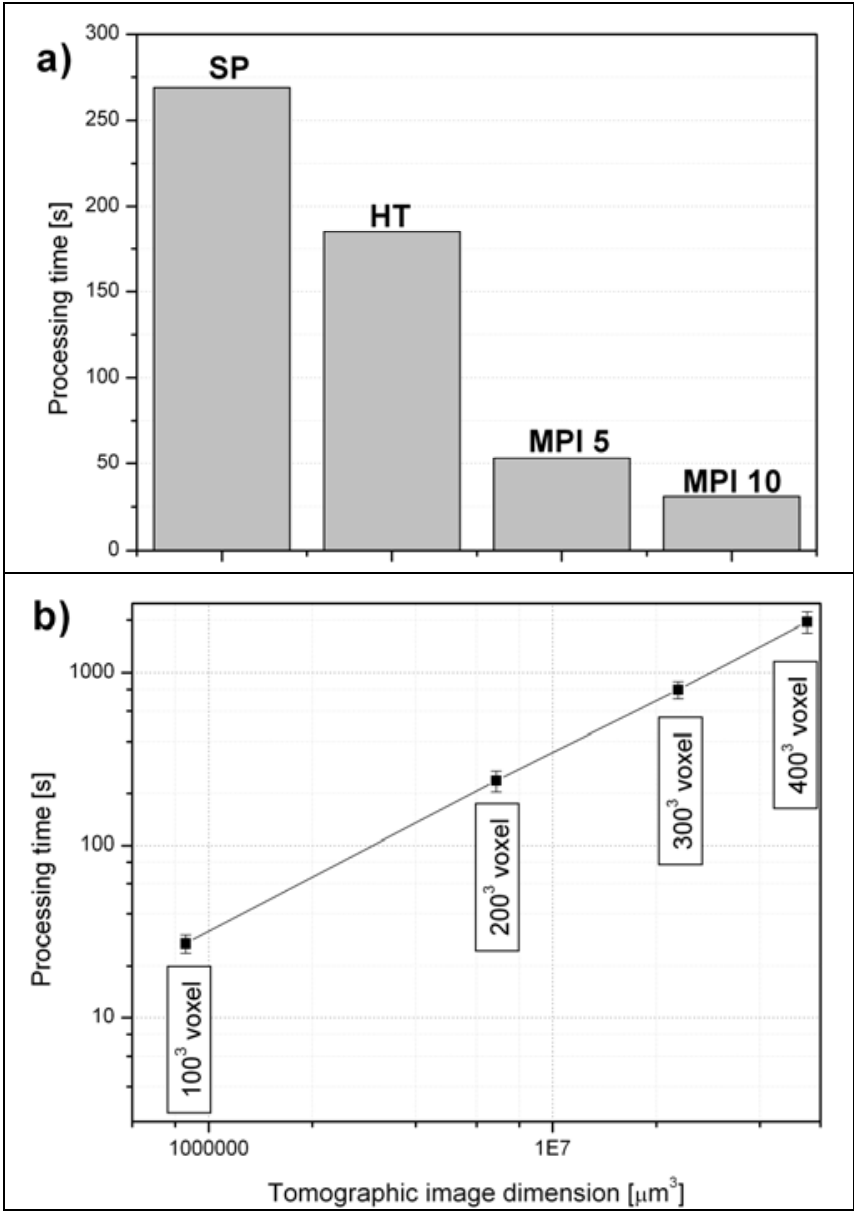

Figure 4 - a) Reduction of processing time achieved with parallel computing for the hysteresis operation on a $100 \times 100 \times 100 \mathrm{SiC}_{\mathrm{p}}$ FGMMC tomographic dataset. SP represents the original sequential processing with a single CPU; HT corresponds to hyperthreading with a single 2-CPU node; whereas MPI designates parallel processing with five 2-CPU nodes equal to the one used for HT; the numbers after MPI correspond to the number of simultaneous processes.

b) Evolution of parallel processing times with increasing $\mathrm{SiC}_{\mathrm{p}}$ FGMMC tomographic dataset volume, under MPI 10 conditions. Each voxel represents a $0.95^{3} \mu \mathrm{m}^{3}$ cube.

Future applications. A novel type of material, syntactic FGMMCs - functionally graded aluminium matrix composites reinforced with hollow ceramic microspheres - is currently being developed at CENIMAT and CIICS. One problem observed arises from the sensitivity of some of the reinforcements to crushing. In the light of this sensitivity, it is not possible to ascertain with 2-D imaging if the occurrence of the Al-alloy inside a particle - as shown in Fig. 5 - involves a fragment of a previously damaged reinforcement or is a manifestation of permeability on the part of an intact microsphere. Solving this type of uncertainty would be within the realm of SXMT, by revealing if aluminium is capable of penetrating intact microspheres within the material.

\section{Summary}

This work reviewed some possibilities of application of X-ray microtomography to the microstructural characterization of Al-based functionally graded materials. For that purpose, examples from the literature, pertaining not exclusively to Al-based FGMs, were presented, illustrating the interest of CT for studying different aspects of the reinforcement population, characterizing interfacial features or gaining knowledge about the evolution of different phenomena. 
Even if conventional CT may be sufficient for some applications, SXMT, given its superior spatial resolution and penetration capacity, constitutes the tool of choice for these studies, provided its two main limitations - scarce synchrotron radiation source availability and large computing capability required for the treatment of the resulting large datasets - can be coped with.

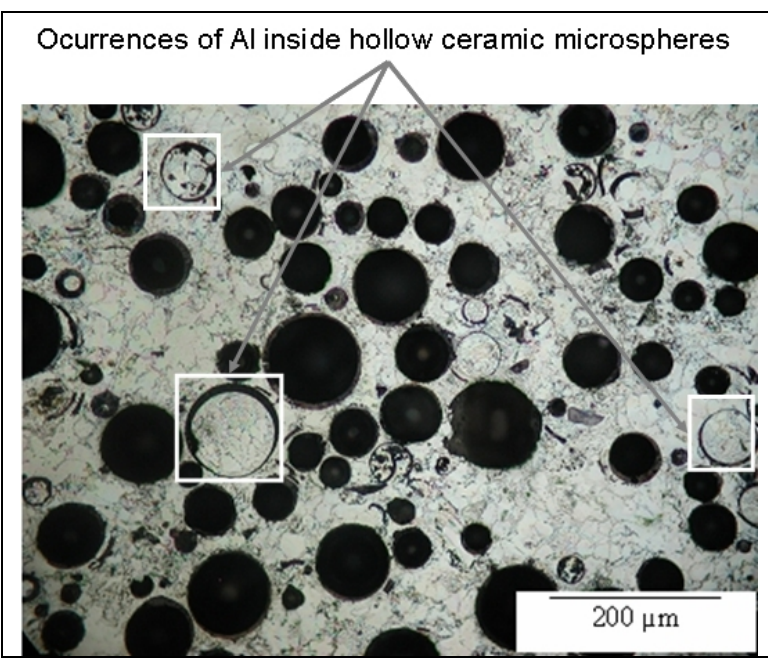

Figure 5 - Optical micrograph of a syntactic FGMMC, showing the presence of Al-alloy inside some of the ceramic hollow microspheres. 2-D imaging does not provide an answer to whether such an occurrence involves fragments of microspheres which had been damaged prior to composite fabrication or if the alloy permeated the walls of intact microspheres.

\section{Acknowledgements}

The authors wish to acknowledge P. Medeiros and P. Quaresma, from CITI (Centro de Investigação em Informática e Tecnologias da Informação/UNL), for their role in the development of the data processing tools. This work was partially sponsored by Conselho de Reitores das Universidades Portuguesas (Portugal) / Conférence des Présidents d’Université (France) (Actions Universitaires Intégrées Luso-Françaises) and by Fundação para a Ciência e Tecnologia (FCT - Portugal) under the program POCI (contract POCI/CTM/56395/2004). The financial support obtained by A. Velhinho from Fundação Calouste Gulbenkian is gratefully acknowledged.

\section{References}

[1] L.A. Rocha, A.E. Dias, D. Soares, C.M. Sá and A.C. Ferro: Ceram. Trans. Vol. 114 (2001), p. 467

[2] L.A. Rocha, P.D. Sequeira, A. Velhinho and C.M. Sá in XVI Congr. Brasil. Eng. Mec. Uberlândia - MG - Brasil, 2001, p 381.

[3] A. Velhinho, P.D. Sequeira, F.B. Fernandes, J.D. Botas and L.A. Rocha: Mater. Sci. Forum Vol. 423-425 (2002), p. 257

[4] A. Velhinho, P.D. Sequeira, F.B. Fernandes, J.D. Botas and L.A. Rocha in XV Congr. Brasil. Eng. Ciência Mater. Natal - Brasil, 2002, p 6.

[5] J.R. Gomes, L.A. Rocha, S.J. Crnkovic, R.F. Silva and A.S. Miranda: Mater. Sci. Forum Vol. 423-425 (2003), p. 91

[6] A. Velhinho, J.D. Botas, E. Ariza, J.R. Gomes and L.A. Rocha: Mater. Sci. Forum Vol. 455-456 (2004), p. 871

[7] J. Baruchel, J.-Y. Buffière, E. Maire, P. Merle, G. Peix, X-Ray Tomography in Material Science, ed. Hermès (2000)

[8] L. Salvo, P. Cloetens et al.: Nuclear Instr. \& Methods in Phys. Res. B Vol. 200 (2003), p. 273

[9] A. Velhinho, G.L. Vignoles, P. Cloetens, X. Thibault, E. Boller, F.B. Fernandes, L.A. Rocha and J.D. Botas: Mater. Sci. Forum Vol. 492-493 (2005), p. 621

[10] E. Masad, S. Saadeh, T. Al-Rousan, E. Garboczi and D. Little: Comput. Mater. Sci. Vol. 34 (2005), p. 406 
[11] A. Velhinho, P.D. Sequeira, R. Martins, G. Vignoles, F.M.B. Fernandes, J.D. Botas and L.A. Rocha: Nuclear Instr. \& Methods in Phys. Res. B Vol. 200 (2003), p. 295

[12] G. Vignoles: Carbon Vol. 39 (2001), p. 167

[13] Y. Watanabe, A. Kawamoto and K. Matsuda: Comp. Sci. and Technol. Vol. 62 (2002), p. 881

[14] L. de Vetter, V. Cnudde, B. Masschaele, P.J.S. Jacobs and J.v. Acker: Mater. Charact. Vol. 56 (2006), p. 39

[15] K. Aldas and M.D. Mat: J. of Mater. Proc. Technol. Vol. 160 (2005), p. 289

[16] D.J. Rowenhorst, J.P. Kuang, K. Thornton and P.W. Voorhees: Acta Mater. Vol. 54 (2006), p. 2027

[17] J.-M. Chaix in Journées d’Automne 2001 So. Franç. Métall. Matér. Paris - France, 2001, p 80.

[18] A. Velhinho, P.D. Sequeira, R. Martins, G. Vignoles, F.B. Fernandes, J.D. Botas and L.A. Rocha: Mater. Sci. Forum Vol. 423-425 (2002), p. 263

[19] R.W. Hamilton, M.F. Forster, R.J. Dashwood and P.D. Lee: Scripta Mater. Vol. 46 (2002), p. 25

[20] O. Coindreau, G. Vignoles and P. Cloetens: Nuclear Instr. \& Methods in Phys. Res. B Vol. 200 (2003), p. 308

[21] M. Faessel, C. Delisée, F. Bos and P. Castéra: Comp. Sci. \& Technol. Vol. 65 (2005), p. 1931

[22] Y. Watanabe, H. Eryu and K. Matsuura: Acta Mater. Vol. 49 (2001), p. 775

[23] W.F. Buckingham and C.S. Cigler: Microstructural Sci. Vol. 18 (1990), p. 111

[24] H. Schwarz and H.E. Exner: J. of Microscopy Vol. 129 (1983), p. 155

[25] N. Silva and A. Velhinho: Mater. Sci. Forum Vol. 514-516 (2006), p. 779

[26] A. Velhinho, F.B. Fernandes, J.D. Botas, G. Vignoles, X. Thibault, P. Cloetens, E. Boller and L.A. Rocha: Mater. Sci. Forum Vol. 492-49 (2005), p. 621

[27] R.H. Mathiesen and L. Arnberg: Mater. Sci. \& Eng. A Vol. A413-A414 (2005), p. 283

[28] G. Reinhart, N. Mangelinck-Noel, H. Nguyen-Thi, T. Schenk, J. Gastaldi, B. Billia, P. Pino, J. Hartwig and J. Baruchel: Mater. Sci. \& Eng. A Vol. A413-A414 (2005), p. 384

[29] O. Lame, D. Bellet, M.D. Michiel and D. Bouvard: Acta Mater. Vol. 52 (2004), p. 977

[30] H.O. Sørensen, B. Jakobsen, E. Knudsen, E.M. Lauridsen, S.F. Nielsen, H.F. Poulsen, S.

Schmidt, G. Winther and L. Margulies: Nuclear Instr. \& Methods in Phys. Res. B Vol. B246 (2006), p. 232-237

[31] D.K. Balch and D.C. Dunand: Acta Mater. Vol. 54 (2006), p. 1501

[32] T. Ohgaki, H. Toda, I. Sinclair, J.-Y. Buffière, W. Ludwig, T. Kobayashi, M. Niinomi and T. Akahori: Mater. Sci. \& Eng. A Vol. A406 (2005), p. 261

[33] E. Pereiro-López, W. Ludwig, D. Bellet and P. Cloetens: Nuclear Instr. \& Methods in Phys. Res. B Vol. B246 (2006), p. 226

[34] A. Steuwer, L. Edwards et al.: Nuclear Instr. \& Methods in Phys. Res. B Vol. B246 (2006), p. 217

[35] J.-Y. Buffière, H. Proudhon, E. Ferrie, W. Ludwig,E. Maire, P. Cloetens: Nuclear Instr. \& Methods in Phys. Res. B Vol. B238 (2005), p. 75

[36] E. Ferrié, J.-Y. Buffière, W. Ludwig, A. Gravouil and L. Edwards: Acta Mater. Vol. 54 (2006), p. 1111

[37] L. Babout, E. Maire and R. Fougères: Acta Mater. Vol. 52 (2004), p. 2475

[38] J.-Y. Buffière, E. Maire, P. Cloetens, G. Lormand and R. Fougères: Acta Mater. Vol. 47 (1999), p. 1613

[39] D.K. Balch, J.G. O'Dwyer, G.R. Davis, C.M. Cady, G.T.G. III and D.C. Dunand: Mater. Sci. \& Eng. A Vol. A391 (2005), p. 408 